\title{
Conceptualising mLearning Literacy
}

\author{
Wan Ng, School of Education, University of New South Wales, Sydney, NSW, Australia
}

\begin{abstract}
Research into the educational application of mobile technologies has increased dramatically in recent years. Much has been written about mobile learning and its various pedagogical practices and issues as well as the theoretical frameworks that have been developed to underpin the studies in the reports. However, little has been written about the literacy associated with learning with mobile devices and whether there is a place for its development in education. This conceptual paper seeks to explore mLearning literacy, the digital literacy associated with learning with mobile devices, and asks the question: What is mLearning literacy and what are its implications for educators? In the paper, the author will argue that fundamental to learning with mobile devices is the need to develop the associated digital literacy in students. The author proposes that being mLearning literate would empower students to learn more independently and more safely when using mobile devices and their applications.
\end{abstract}

Keywords: Development of MobileLearning in Education, Digital Literacy, Learning with Mobile Devices, Mobile Devices, Mobile Learning Literacy (mLearning Literacy)

\section{INTRODUCTION}

Research into the educational application of mobile technologies has picked up dramatically in the last few years. $\mathrm{Ng} \&$ Nicholas (in press) reported on a sharp increase in research publications in this area of learning in the years 2004-2007, with $88 \%$ of the articles published in the 5 years from 2006-2010 (see Figure 1). They stated that these figures underestimate the amount of work in the field, since, for example, reports for numerous large funded projects in the late 1990s and early 2000s in the US, UK and Europe were not located in the databases used. Their literature search indicated substantial variation in the types of mobile technologies used and the contexts in which they were used.
The diversity in frameworks used in mobile learning studies include knowledge building (e.g. Chen \& Huang, 2010), personal construct theory (e.g. Chu, Hwang, \& Tsai, 2010), media richness (e.g. Shim, Shropshire, Park, Harris, \& Campbell, 2007), mLearning (e.g. Evans, 2008; Franklin, Sexton, Lu \& Ma, 2007), cognitive load (e.g. Hung, Lin \& Hwang, 2010), informal learning (e.g. Clough, Jones, McAndrew, \& Scanlon, 2008), mobile computer supported collaborative learning (e.g. Huang, Yang, Huang, \& Hsiao, 2010), experiential learning (e.g. Dyson, Litchfield, Lawrence, Raban, \& Leijdekkers, 2009), lifelong learning (e.g. Dale \& Pymm, 2009) and ubiquitous learning (e.g. Tsai, Tsai, \& Hwang, 2010). Mobile learning theoretical frameworks are

DOI: $10.4018 / j \mathrm{mbl} .2013010101$ 
Figure 1. Number of mobile learning papers from 2000-2010 (Ng \& Nicholas, in press)

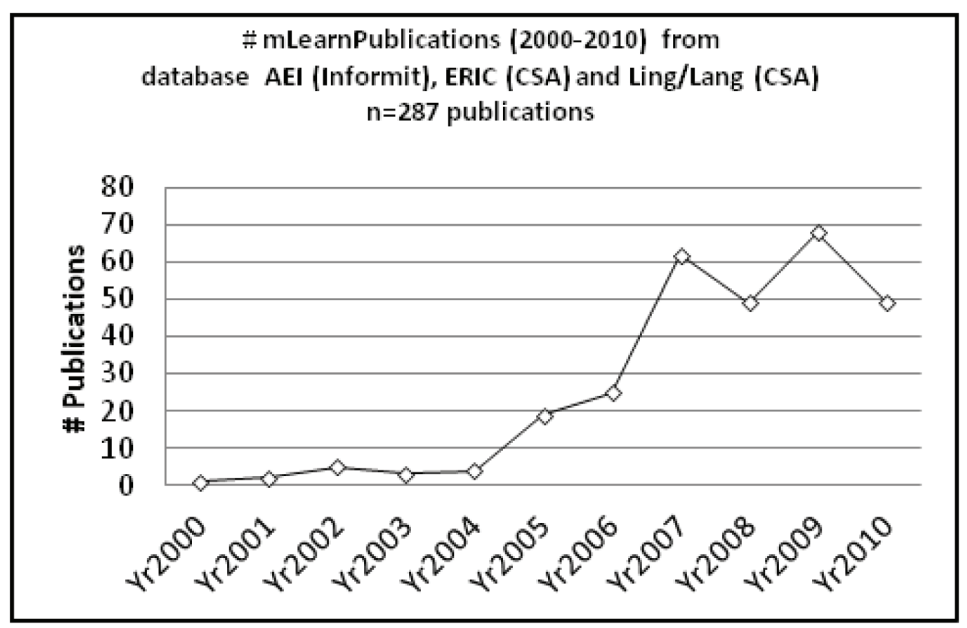

often adapted from general ICT-based or other learning theories and modified for mobile learning. The more popular theories that have been adapted for mobile learning are socio-constructivist learning theory (e.g. Cochrane \&

Bateman, 2010; Motiwalla, 2007), activity theory (e.g. Liaw, Hatala \& Huang, 2010) and situated and authentic learning theories (e.g. Gkatzidou \& Pearson, 2009; Looi, Seow, Zhang, So, Chen, \& Wong, 2010). Most of the frameworks also include a focus on personalised learning. Others relate to the social aspects of learning at the collaborative level (e.g. Sharples, Taylor, \& Vavoula, 2007; Shih, Chuang, \& Hwang, 2011). At the more technical levels researchers explored human-computer interactions (e.g. Sitthiworachart, 2007) and contextaware ubiquitous learning (e.g. El-Bishouty, Ogata, \& Yano, 2011).

Apart from the rise in publication output, the increased interest in mobile learning can also be seen from the increased number of mobile learning conferences where five dedicated conferences that run regularly have been set up in recent years. These are the Wireless, Mobile and Ubiquitous Technologies in Education Conference, IADIS International Conference on Mobile Learning, International Conference on Interactive Mobile and Computer Aided Learning, MLearn Conference and APAC Mo- bile Learning and Edutainment Conference. In addition, specialised mobile learning and research centres such as the London Mobile Learning Group (http://www.londonmobilelearning.net) and Learning2Go (http://www. learning2go.org/) have increased the visibility of learning with mobile technologies. The number of journals dedicated to mobile learning has also increased. 2007 saw two new journals: the International Journal of Mobile Learning and Organisation and the International Journal of Interactive Mobile Technologies, and the International Journal of Mobile and Blended Learning was launched in 2009.

While the field is expanding, crucial issues underpinning practices and their sustainability remain to be addressed such as the role of teachers and the type of professional development required to prepare them for teaching their students to learn with these devices. There is also a lack of argument for the pedagogy that connects formal and informal learning with mobile devices and the sustainable use of these devices for learning in relation to factors such as policy, infrastructure and technical, administrative and community support. The diversity of contexts, devices and theoretical frameworks for mobile learning indicates that there is no consolidated view of how to sustain the practices and learning with mobile devices. 
While there are studies that explicitly mention teaching the participants how to use a particular program for a given project, in general, there appears to be an underlying assumption, in many of the studies, that learners have the necessary skills, knowledge and attitudes to use mobile technologies for learning. Little about the literacy associated with interacting and learning with mobile technologies has been written or incorporated into the frameworks of the studies. A fundamental issue that this paper seeks to explore is the literacy of learning with mobile devices, henceforth known as mLearning literacy. It seeks to define what mLearning literacy is and what it entails and argues that mLearning literacy is the sustainable component related to mobile learning for formal, informal and lifelong learning.

In order to understand the literacy associated with learning with mobile technologies, we need to have some understanding of the affordances mobile devices offer for learning and the theories that underpin the learning. In the next section, the affordances of mobile devices as social and pedagogical tools for learning will be discussed. As mobile devices are also personal tools, both for learning and for conducting everyday activities such as problem solving, a discussion of these aspects will also be provided in order to have an insight into the mLearning literacy needed in informal contexts. As Littlejohn, Beetham and McGill (2012) discussed in their review of digital literacies in theory and practice, literacy needs to consider learning beyond formal education.

\section{MOBILE DEVICES AS SOCIAL, PEDAGOGICAL AND INFORMAL LEARNING TOOLS}

Mobile learning (mLearning) has been conceptualised differently by different researchers. Definitions of mobile learning have focused on access, mobility and support for learning in multiple locations without physical network connections (e.g. Geogiev, Georgieva \& Smrikorov, 2004; Parsons, 2007). Contexts, space and time have also been used to define mobile learning (Pachler, 2009; Sharples, Taylor \& Vavoula, 2007), for example Pachler (2009) asserts that mobile devices are enablers for users to "re-interpret their everyday life contexts as potential resources for learning" (p.5). Other researchers have emphasized the ubiquity of learning (e.g. Hedin \& Norén, 2009; Evans, 2008; Goodchild \& Chenery-Morris, 2011) and the requirements for it to occur, for example Chen, Kao, Sheu \& Chiang (2002) and Ogata \& Yano (2004) have identified the requirements as permanency, accessibility, immediacy, interactivity, situated instructional activities, and adaptability. These requirements depend largely on wireless connectivity in the learning contexts and their characteristics are strongly enabled by the educational affordances that mobile technology increasingly offers. The emphasis on portability and learning in both formal and informal contexts in these mLearning definitions are perspectives that define mLearning in this paper.

According to CNET news, mobile phones, iPhones and phones with android operating systems are on the rise (Whitney, 2009). BBC online (2008) reported Neilson's finding of a $25 \%$ increase in mobile Internet usage compared to just 3\% increase in desktop access for 2008 ( $2^{\text {nd }}$ and $3^{\text {rd }}$ quarters of the year). It also found that mobile net users were younger and searched for different things on the Internet. The increase is attributed to the cheaper mobile phone rates, improved network technology and more userfriendly mobile phones. Tablets are also on the rise. As reported ${ }^{1}$ by CNET Tech Review, the year 2010 saw the tablet wars heating up between new tablets from Acer, the Samsung Galaxy Tab and Apple's iPad ${ }^{2}$ device. In the context of this paper, mobile devices are those that are easily portable by learners of all ages and with easy access to the Internet. In consequence, they are handheld and constrained in their processing capacity. The definition includes mobile phones, smartphones, personal digital assistants (although PDAs are progressively becoming obsolete as they are replaced by smartphones), iPods, MP3 players and tablets (including iPads and the array of recently released Android-based 
tablets) but excludes laptops and notebooks. This paper makes a case that while there are similarities in the digital literacies associated with mobile devices and laptop/desktop usage, the ease in portability and constraints in size and processing power associated with mobile devices make mLearning literacy a specific and differentiated construct.

\section{Mobile Devices as Social Learning Tools}

A significant part of Web 2.0 is its social web with online tools that allow people to learn by:

1. Networking socially e.g. through Facebook, Ning, Twitter, Skype and other similar social network sites. Students are able to discuss projects and homework with their peers and sometimes with their teachers using these facilities via their mobile devices as long as those devices have Internet access.

2. Reading, writing and editing in collaborative knowledge construction activities e.g. through wikis, GoogleDocs and cMaps and

3. Sharing ideas and information e.g. through blogs, slideshare, podcasts (via iTunes or uTunes), videos on YouTube or contribute comments and opinions to online newspapers or discussion forums.

The increased capacity to network with more learners and experts via Web 2.0 together with the 'always on' capability of mobile devices mean that learners are able to access more resources and interact more frequently with people to enhance their learning. The importance of a social context created through being connected for the construction of knowledge has been emphasised in socio-constructivist (Bruner, 1986; Vygotsky, 1978), socio-cultural(John-Steiner \& Mahn, 1996) and connectivist (Siemens, 2005) theories of learning. Connectivism is a relatively new concept and proposes that knowledge is distributed across an information network and across multiple individuals and that learners connected to a learning community benefit from it, while also contributing information to it (Boitshwarelo, 2010). A central tenet of these theories is that the learning process involves interactions with other individuals (peers, teachers, experts, friends, family and even strangers) where culture and society will influence the learning. In online learning environments, the communicative and collaborative experiences provide opportunities for the individual to reflect on his/her own prior knowledge and restructure misconceptions and/or build new understanding in his/her cognitive schemas. These learning theories support learning with mobile devices where connectivity (for social interactions) is one of mobile technologies' best serving features. As Gawelek, Spataro and Komarny (2011) asserted, the desire to stay connected will continue to move people toward mobility.

A more explicit mobile learning theory that is adapted from the conversation theory of Pask (1976) is the Conversational Learning theory (Sharples, Taylor, \& Vavoula, 2007) that focuses on the communicative interactions between systems (e.g. technology and people) for the exchange of knowledge. The theory views learning as dynamic conversational processes taking place across multiple contexts (technology with technology; technology with person; person with person) within systems where people and technology are in 'continual flux'. Another variation of Pask's conversation theory is Laurillard's (2002) Conversational Framework that focuses on the learner-teacher cognitive systems and the process of negotiations between them of views/ideas associated with the subject matter being taught/studied so as to modify the learners' perceptions (Atherton, 2011). Technology in this case provides the environment for conversations to take place and for learners to demonstrate understanding. Implicit in these conversational theories for mobile learning are theories of constructivism (constructing knowledge at the individual level e.g. through reflections), socio-constructivism and connectivism (interactions with instructor/ peer through networked communities) and situated-learning (Brown, Collins, \& Duguid, 1989; Lave \& Wenger, 1990) that is, learning as it normally occurs and in context. 
Figure 2 shows a representation of social learning that is mediated by mobile technology and the dynamics between systems (e.g. teacher, student, technology). Examples of conversations are instructions, discussions and feedback that could be text-based messages/ dialogues and/or in audio/verbal formats. The inherent ubiquitous characteristics of mobile technologies would facilitate faster communicative and collaborative experiences through their capacity to connect and respond to others in timely (anytime, anywhere) ways to share knowledge, ideas, opinions and experiences with individuals or dedicated online communities, hence optimising the individual's learning. As most of the socialising and/or learning with mobile devices in networked social sites takes place informally, educators need to consider how best to prepare and support students to learn in this context. However, due to the size and limited capacity of mobile handsets, information would need to be chunked and 'dialogues' between learners via their mobile devices would need to be succinct and focused. In such learning environments, critical thinking skills and metacognitive processes are important. Soft skills (e.g. communicative and interpersonal skills) for interacting in mobile communities are also necessary, such as when negotiating views that are contradictory.

The connectivity embraced in the conceptualization of mLearning literacy in this paper is not limited to Internet connectivity as Internet connection is not a given. Particularly in developing countries, connectivity is mostly via mobile phones and mobile networks. For example, social/pedagogical uses of mobile phones based on text messages are reported in projects such as the The Jokko Initiative - Senegal ${ }^{3}$ (collaborative work between UNICEF and Tostan in West Africa that through the use of mobile phone text messages aims to encourage group decision-making in Senegalese villages), SMS4Learn ${ }^{4}$ (work using SMS in Afghanistan to support training) and $m$ Health, e.g. collaborative efforts between Cambridge University and China Mobile to capitalise on the potential of mobile phones to deliver healthcare in China and worldwide ${ }^{5}$. An example that is not from a developing country, but rather part of school-based learning through mobile networking is the Mobile-Assisted Mobile Learning (MALL) initiative of the Irish National Council for Curriculum and Assessment that made use of mobile phones and text-based web chat to facilitate the learning of the Irish language (Keogh, 2011).

\section{Mobile Devices as Pedagogical Tools}

The social learning enabled by mobile technologies discussed above is itself an aspect of mobile-enabled pedagogy, that is, teachers are able to design situated, authentic learning activities, project work or problem solving tasks that necessitate dialogues between members of the team via mobile devices. Laurillard (2007) asserted that mLearning experiences, as interpreted through the Conversational Framework can be richer, for example, mobile devices are able to digitally facilitate the link between students and data while they are in site-specific practice environments. In addition, learning with mobile devices motivates students pedagogically with reasons including control and ownership of the learning, fun, contextual learning and continuity in learning between contexts.

Mobile devices as pedagogical tools have been reported in numerous studies (e.g. Herrington, Herrington, Mantei, Olney, \& Ferry, 2009; Laurillard, 2007; Ng, 2011a; Nicholas $\& \mathrm{Ng}, 2009$; Orr, 2010). They have the capacity to support the blurring of the boundaries between formal and informal learning, such as information storage and retrieval capabilities, access to the Internet via wireless and/or $3 \mathrm{G} / 4 \mathrm{G}$ networks, and applications that support learning and portability. Keegan (2005) asserts that small size, easy portability, user friendliness, affordability and personal ownership are all important characteristics of a mobile device to support mobile learning. Cheung and Hew (2009) and Laurillard (2007) summarized the pedagogical uses of mobile devices as tools for communicat- 
Figure 2. Mobile technology mediated conversations

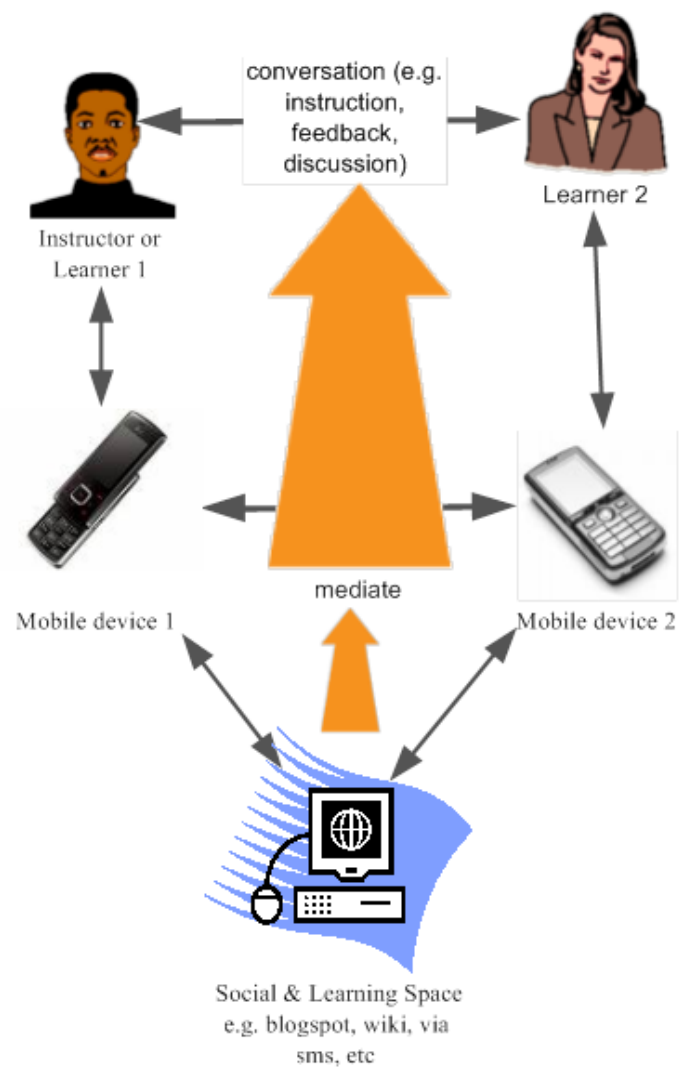

ing and sharing, investigating, capturing data, analysing, assessing, task managing, accessing multimedia and representing meanings. Each of these characteristics involves understanding and choice-sometimes between options and sometimes within features. Appropriate understandings to make appropriate choices, connections or ways of engaging with the technologies are part of mLearning literacy. In Table 1, the features supporting these pedagogical affordances are summarized. The extent to which mobile devices can be used pedagogically is dependent on the features in the different mobile devices, for example mobile phones with no Internet capability will be limited to communication via text messages and for most mobile phones, audio-recording of voice/sounds and capturing of images and videos.

The pedagogical affordances offered by mobile devices mean that content can be delivered in textual, audio and visual formats or in combined multimedia format, the latter being the multimodal means of representing information and knowledge. Information represented in multiple modes has the capacity to cater to the different learning needs of students $(\mathrm{Ng}$, 2012) but contains within it potential for contradictions, multiple readings and greater sources of ambiguity or confusion. As the world is becoming increasingly multimodal, understanding and developing capacities to represent meanings in different modes is an important aspect of mLearning literacy. 
Table 1. Features of mobile devices that support pedagogy (modified from Ng, 2011b)

\begin{tabular}{|l|l|}
\hline \multicolumn{1}{|c|}{ Mobile device(s) } & \multicolumn{1}{c|}{ Pedagogical enabling capacities } \\
\hline $\begin{array}{l}\text { Personal digital assistants } \\
\text { (PDA); tablets (iPads and } \\
\text { android tablets e.g. Samsung } \\
\begin{array}{l}\text { Galaxy Tab, Optus My Tab, } \\
\text { Telstra Tab) }\end{array}\end{array}$ & $\begin{array}{l}\text { Computing capabilities include software: mobile word processing (Word/Pages), } \\
\text { spreadsheet(Excel/Numbers), PowerPoint/Keynote for presentation; Internet access } \\
\text { via Wifi/3G/4G; Bluetooth files; audio and video record; capture images; eBook } \\
\text { for reading, operate and/or display multimedia learning resources and apps, games; } \\
\text { geospatial positioning for navigation; task management software for organization } \\
\text { and managing time/tasks e.g. calendar, Notes. Tablets have communication capabili- } \\
\text { ties such as emailing, Internet access social sites and video calls e.g. Skype, Tango }\end{array}$ \\
\hline $\begin{array}{l}\text { Mobile/cell phones; smart- } \\
\text { phones e.g.iPhones and android } \\
\text { mobile phones }\end{array}$ & $\begin{array}{l}\text { Communication capabilities for voice or text messages; access the Internet via } \\
\text { Wifi/3G/4G for video calls e.g. Skype, Tango. Other computing capabilities - send } \\
\text { files via Bluetooth; audio and video record; capture images; display multimedia } \\
\text { resources and other media players; operate educational apps and games that sup- } \\
\text { port learning; geospatial positioning for navigation; task management software for } \\
\text { organization and managing time/tasks }\end{array}$ \\
\hline $\begin{array}{l}\text { Digitalmediaplayers (iPods and } \\
\text { MP3/MP4 players) }\end{array}$ & $\begin{array}{l}\text { Access the Internet; cameras (in 4G iPod Touch) for image capture; audio record; } \\
\text { play music, display multimedia resources using media players; operate educational } \\
\text { apps and games }\end{array}$ \\
\hline
\end{tabular}

\section{Mobile Devices as Personal Tools for Conducting Everyday Activities and Learning Informally}

The pervasiveness of mobile technology reflects its ability to "strengthen and multiply communicative relationships - between ideas, especially as a feature of non-linearity and hypertext, as well as between people" (Nixon, Atkinson and Beavis, 2006,p.133). Much of this 'multiplicity of communicative relationships' for learning or socialising takes place informally through mobile networks or wireless access to the Internet. Consistent with this, the young people of today are often described as comfortable with using digital technologies, embracing them in their everyday lives and are frequently online users, networked socially through technology to stay in contact with friends, family and peers via email, mobile phones, SMS, MSN, video conferencing, discussion boards and chatrooms. They are described as part of $\mathrm{Web}$ 2.0's online communities where they socialise or collaborate to discuss a topic or an issue (for example through blogs, Facebook, Skype or VoiceThread) or make use of online tools to create and share information (for example through wikis, Slideshare and YouTube).

Mobile devices are also personal tools to carry out everyday activities, hence another aspect of learning in everyday contexts is the ability to use appropriate applications to seek for more information (e.g. QR code reader, GPS for direction) to solve problems encountered. The individual needs to develop the necessary critical thinking required to use the applications effectively. They also need to develop soft skills (e.g. communicative and interpersonal skills) for interacting in mobile communities, such as when presenting views that are contradictory or negotiating with a stranger (purchaser or seller) verbally or via text messages about a product on eBay and deciding on when and where to meet. Being mLearning-literate would enable the individual to make better and more effective use of mobile devices to conduct everyday activities and to learn informally. In this respect, mLearning literacy skills are also life skills associated with a person's day-to-day living.

\section{CONCEPTUALISING MLEARNING LITERACY}

Literacy has, over the last two decades, moved conceptually beyond the view of being equipped with the technical skills of reading, writing and being numerate to a pluralist notion that includes vital competencies such as the ability to identify, understand, interpret, create, 
communicate and compute texts (written and printed material) in the varying contexts of an individual's personal life and in the wider community (UNESCO, 2004, p.13). Furthermore, the practice of literacy has been framed as social practices that are situated in and shaped by social and cultural contexts from which they derive their meanings (Street, 1995; Littlejohn et al, 2012). The advancement of digital technologies with their social enabling capabilities (e.g. Web 2.0; social networks) will only affect this practice in a more pronounced manner. In addition, texts in a digital world are no longer confined to just written text but include visuals (e.g. images, signs, videos), sound (e.g. lectures, conversations, music) and multimodal formatted artefacts (e.g. simulations, games and multimedia resources). As a result of the influence of technology on meaning making, the concept of 'literacy' has evolved over the last two decades to concepts of 'new literacies' (Lankshear \& Knobel, 2003; Leu, Kinzer, Coiro, \& Cammack, 2004; Semali, 2001) and the literacy plurality of 'multiliteracies' (The New London Group, 1996). The latter concept advocates that learning from texts, images, maps, videos, podcasts and multimedia resources involves linguistic, visual, spatial, audio and multimodal literacies, which are collectively a part of the framework known as 'multiliteracies'. The concept was first conceived by the New London Group (1996) to highlight two arguments that are influenced by globalisation and technology: (i) the significance of cultural and linguistic diversity and (ii) the multiplicity of communication channels. The former argument asserts that as today's society becomes more linguistically and culturally diverse, meaning making differs according to cultural, social and professional contexts while the latter suggests that media and communication technologies enable meaning making to be increasingly multimodal where the written-linguistic modes integrate visual, audio, gestural and spatial patterns of meaning.

'New literacies' is attributed to the new types of knowledge associated with "digitally saturated social practices", such as blogging (Lankshear \& Knobel, 2003). Lankshear \&
Knobel (2007) made the point that new literacies must have both new "technical stuff" and "ethos stuff" since new technologies afford new practices and central to new literacies are these practices and the contexts (local and global) in which they are situated. Similar to The New London Group's (1996) argument, Lankshear \& Knobel (2003) stated that a shift in educational mindset is necessary to embrace 'new literacies' education in order to take into account the changes the world has experienced during the information technology revolution. In this respect, new literacies are adaptive literacies that will continually evolve as new technologies emerge. Being digitally literate will prepare individuals to adapt to new and emerging technologies more easily and as mobile technologies are one of the fastest growing areas of technology, equipping individuals with mLearning literacy should enable them to pick up newly emerging semiotic systems and resources for communication as they arise and adapt to new mindsets and practices that come with this growth.

The mLearning literacy advocated in this paper is the literacy of mobile learning. In conceptualizing mLearning literacy, the questions asked are: What are the capabilities that are required by individuals to make use of mobile technologies for learning in formal, informal and social contexts? and, what are the attitudes and affective attributes that individuals need to adopt to learn with mobile tools?

Learning with mobile technologies has similarities with learning with digital technologies in general, that is, desktop/laptopbased technologies in which the learning is supported by frameworks of digital literacy. Thus, mLearning literacy is digital literacy associated with the use of mobile devices for learning. It can be regarded as a subset of digital literacy. The notion of learning in this paper is about understanding subject matter (content/ concepts) and being able to demonstrate that understanding and its application (of acquired subject-related knowledge and skills) to solve problems, aided by mobile devices and their associated resources. In the informal context 
that includes lifelong learning, learning that is mediated by mobile technology includes the development of life skills for independent learning and solving everyday problems through the use of mobile resources. The focus on learning means that mLearning literacy is connected to, but different from, 'mobile literacy'. For example Parry's (2011) mobile literacy is largely associated with navigating and understanding social media space that is amplified through the power of the mobile web. The three elements in Parry's mobile literacy are understanding (i) information access (ii) hyperconnectivity and (iii) the new sense of space. In the Adaptive Path's Mobile Literacy project (Alani, 2009), mobile literacy is about understanding the impact of mobile technology and how developed concepts for new mobile phones can work more effectively in emerging markets e.g. language learning in India. Murphy's (2010) concept of mobile literacy for librarians is also broad but aligns more closely with the mLearning literacy framework of this paper. His mobile literacy framework includes being technically familiar with mobile technologies and knowing ways to apply them, being aware of the impact of mobile technologies and understanding the trends and expectations of mobile cultures. The mLearning literacy framework embraces some of the elements in the mobile literacy frameworks mentioned above and breaks them and other dimensions down further by identifying the central purpose of the literacy as the support for learning.

As the mLearning literacy framework acknowledges digital literacy as the superordinate concept for mLearning literacy, it is appropriate to first define digital literacy and then present the mLearning literacy framework where the points of variation from digital literacy will be discussed.

\section{Digital Literacy}

Almost all definitions of digital literacy have a focus on equipping the individual with capabilities for living, learning and working in an increasingly digital culture (e.g. Beetham, McGill\&Littlejohn, 2009; ETS, 2007; Hague \&
Payton, 2010; Martin, 2005). These capabilities are encapsulated in the digital literacy framework formulated by the European Information Society (Martin, 2005, p. 135) which states that:

Digital Literacy is the awareness, attitude and ability of individuals to appropriately use digital tools and facilities to identify, access, manage, integrate, evaluate, analyse and synthesize digital resources, construct new knowledge, create media expressions, and communicate with others, in the context of specific life situations, in order to enable constructive social action; and to reflect upon this process.

In addition to capabilities, attitudes toward using digital technology for learning are important as indicated by Littlejohn et al. (2012), who commented on the limitations of competency in being digitally literate and advocated the adoption of an "evaluative personal stance toward technology that will elevate digital capability from a rapidly obsolescent set of technical skills to lifelong knowledge practice" (p. 7). In their frameworks for digital literacy, Eshet-Alkalai (2004) and $\mathrm{Ng}$ (2012) referred to attitudes and affective attributes as the social-emotional dimension of digital literacy.

Other definitions of digital literacy capture the multimodality of representations in learning more explicitly e.g. in the British Futurelab' handbook on Digital Literacy Across the Curriculum (Hague \& Payton, 2010, p.2) it is stated that digital literacy is:

the ability to make and share meaning in different modes and formats; to create, collaborate and communicate effectively and to understand how and when digital technologies can best be used to support these processes.

Defining digital literacy at more specific levels, Eshet-Alkalai(2004) suggested that there are five types of literacies that are incorporated within the term 'digital literacy', these being (i) photo-visual literacy (ii) reproduction literacy - the art of creative duplication (iii) branching literacy - the creation of non-linear medium 
of information (iv) information literacy and (v) socio-emotional literacy. These multiple literacies and the skills, competencies and the social-emotional perspectives of digital literacy that are indicated in the definitions above have been integrated into a digital literacy framework by $\mathrm{Ng}$ (2012) that will form the basis for the mLearning literacy framework of this paper.

\section{mLearning Literacy}

The mLearning literacy framework shown in Figure 3, is adapted from the digital literacy framework of $\mathrm{Ng}$ (2012). It is made up of three dimensions: technical - relating to technical and functional skills, cognitive - relating to critical thinking, evaluative and multiliteracies capabilities and social-emotional - relating to attitudes, ethical knowledge, social skills and safeguarding capabilities in mobile learning environments. Within and in-between each dimension are multiple literacies that indicate the skills and capabilities to be developed to be mLearning-literate (see Figure 3).

\section{Technical Dimension of mLearning Literacy: Technical and Functional Skills}

At the technical level, the mLearning-literate individual is able to differentiate between the different mobile devices and how they differ technically and functionally as well as understands the affordances and limitations of applications in mobile devices. (S)he:

- Is able to use input and the connecting peripheral devices such as touch screen keypads, navipad, stylus, half-QWERTY keyboard, earphones, Bluetooth headset, USB connector, printer, smartboard

- Has knowledge of working parts for example, infra-red, Bluetooth, wireless, memory card, data synchronization, to configure basic device settings, to use 'Settings' to control features such as sound, brightness; use of multiple windows. General understanding of standard device keys and controls such as soft-keys/navipad, how

Figure 3. The dimensions of mLearning literacy (adapted from $\mathrm{Ng}, 2012, \mathrm{p56}$ )

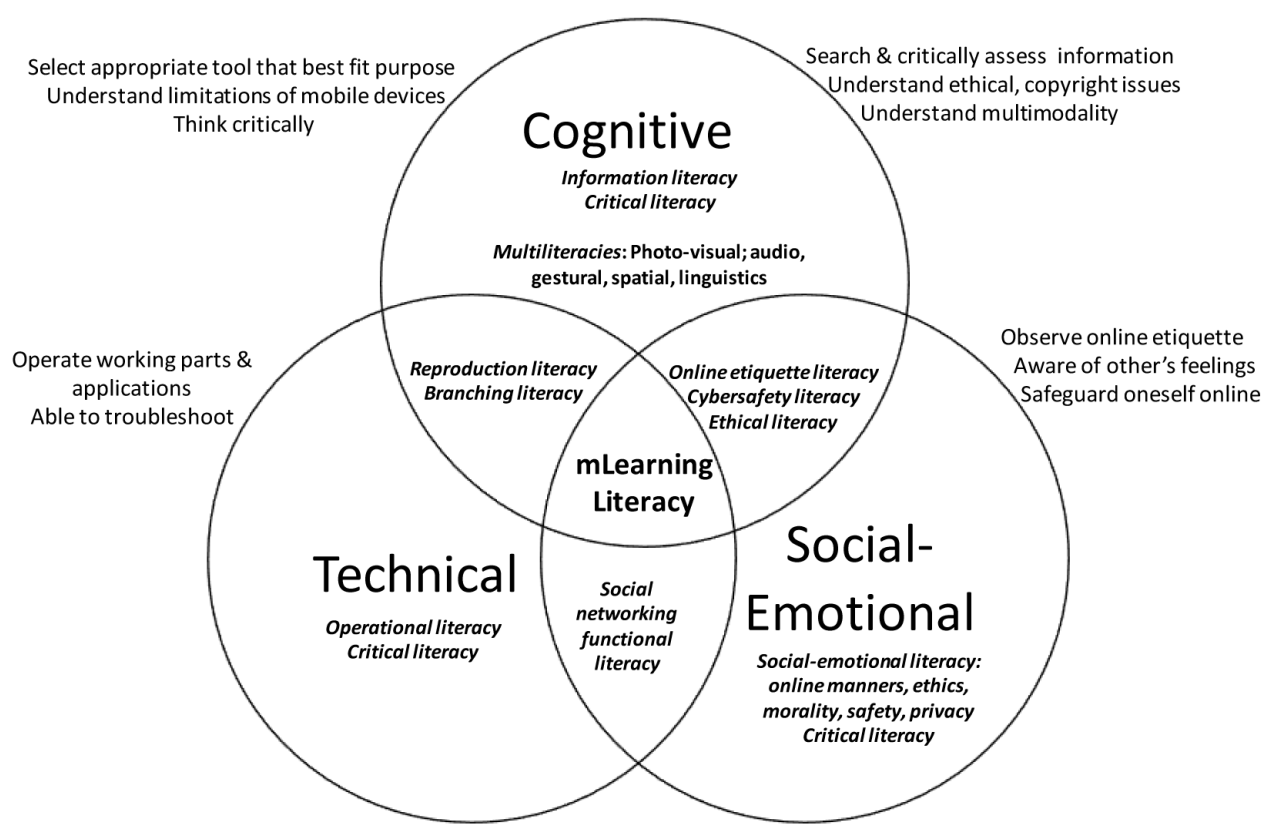

Copyright $(\underset{2013}{2}$, IGI Global. Copying or distributing in print or electronic forms without written permission of IGI Global is prohibited. 
they differ for various devices and ability to successfully locate the equivalent keys on new devices to make calls or send SMS

- Is able to troubleshoot by reading manuals, accessing local Help functions and/or web-based resources (e.g. Youtube) for assistance. For example, keying the right questions or phrases into a search engine would enable the individual to retrieve responses in the form of text, images and/ or videos that will provide explanations to address the problem

- Is able to operate mobile hardware adequately by:

- Understanding file structures e.g. folders and directories and managing where files are located in the drive/ memory card and how to access your drive via the computer (understanding about operating system compatibility)

- Managing data transfer that includes understanding file sizes e.g. audio/video files often in MB and space to hold files; finding, downloading, uninstalling/deleting and installing applications that are compatible with the mobile device, update/change user account information on the device and on the Internet; understand data charge costs associated with downloading data; sending and retrieving attachments, opening them with appropriate applications, unzipping (e.g. Using Pocket RAR), use infra-red and Bluetooth for file transfer; understand limitations of word processing, spreadsheet and presentation tools and compatibilities of operating systems and transferability of files between systems

- Knowing about and able to locate available user interface elements i.e. cues that define interactivity e.g. menu, sizing, scrolling, using sliders, understanding tabs and their relationship to content; use of multiple windows for multitasking

- Set up and use communication tools e.g. e-mails, web mail, VOIP, Blogs, wikis, Facebook, Twitter, send SMS, MMS

- Ensuring that anti-virus software is regularly updated to avoid spam and viruses

- Is proficient in using mobile applications and resources for learning, creating and solving everyday problems. This includes being able to navigate through applications and Web-based resources and select the most appropriate features to accomplish specific tasks.

Developing proficient mLearning technical and operational skills means that the individual needs to spend time exploring new applications and be provided with opportunities to practice such as through repeated use e.g. of mobile spreadsheets or presentation tools.

\section{Cognitive Dimension of mLearning Literacy: Critical Thinking, Evaluative and Multiliteracies Capabilities}

Crucial cognitive skills necessary for the development of mLearning literacy are those associated with using information from the Web, collectively known as information literacy. An mLearning-literate individual would use the Internet effectively for information gathering and synthesis by:

- Being able to search, locate and assess web-based information i.e. Use appropriate browser and search engine, critique information through analysing and evaluating the digital content for accuracy, currency, reliability and level of difficulty

- Understanding that most websites are not mobile friendly nor created for mobile devices and that a fair amount of scrolling (up and down, left and right) will be needed to read information on the web

- Understanding that mobile web pages could contain reduced versions of non-mobile web pages and that a balanced perspective of the article may not be complete

- Understanding about critical literacy and that people behind the scene writing the 
information have their own motivations and to be able to critically evaluate whose voice is heard and whose is not is important for learning as neutrally as possible

- Knowing about the ethical and moral issues associated with reproduction of digital resources, for example copyrights and plagiarism

- Being able to synthesise new understandings using appropriate online (e.g. wiki) or offline (e.g. Keynote, Mobile Word etc) applications that will convey the meanings in the best way

- Understanding that the capacities of productivity applications are reduced in mobile devices

- Understanding the terms and conditions of applications and resources well so that legal liability is avoided

- Conducting strategic interactions that ensures safety e.g. when meeting the purchaser or seller (e.g. trading through ebay) either online or via mobile phone communication to exchange goods and payment.

Within the cognitive dimension of mLearning literacy is multiliteracies - the ability to decode information that is text-based as well as information from images, sound bytes, videos, maps and models - these involve multiliteracies skills that are linguistic, visual, audio, spatial, gestural (as captured in videos) and multimodal (as in multimedia resources e.g. simulations and other Web 2.0 artefacts such as glogs which are online posters). The ability to select the right tool to create and demonstrate understanding is a part of the cognitive dimension, for example in the creation of a one-page/slide presentation on an iPhone or iPad or in the decision whether the Phoster (poster creation application) or Keynote (a presentation application) would better represent the individual's thinking. The mLearning-literate individual would need to weigh and differentiate between the affordances and limitations of the different mobile devices and the types and capacities of the applications they support in order to select the most appropriate tool to complete the set task. Due to the limitations in size and processing power, mobile devices are generally good for content consumption (Internet search, eBook reader) but are more laborious to use for content creation. For learners using mobile devices that are not Internet accessible e.g. mobile phones, GPS and iPods/MP3 players, multiliteracies play an equally important role e.g. the ability to critically decode sound such as music or a podcast (involving audio literacy), read maps and estimate distances (involving spatial literacy) or interpret SMS messages or images and videos sent via MMS (involving verbal and multimodal literacies).

As critical literacy is an important component of all the three dimensions of mLearning literacy, it will be discussed in a separate section following the discussion of the social-emotional dimension of mLearning literacy.

\section{Social-Emotional Dimension of mLearning Literacy: Attitudes, Ethical Knowledge, Social Skills and Safeguarding Capabilities}

Millions of young people 'meet' online on a daily basis to chat, exchange ideas, communicate socially and collaborate on projects. Web 2.0 technologies such as Wikispaces, Flickr, MySpace, Google+, Blogspot, Facebook and YouTube are enabling individuals to contribute freely to networked communities for learning and/or for socializing. Web 2.0 is becoming a lifestyle for young people who are accessing the Web to send emails, seek information, purchase goods, do online banking, chat online, post questions, contribute solutions, post photos and videos, download games, videos and music and write blogs and wikis to share ideas and opinions. These practices are enhanced through nearly-ubiquitous mobile technologies. As Web 2.0 environments become more and more of a lifestyle for young people, the issue of cyber safety and potential risks in participating online is increasing (Conroy, 2007; Hanewald, 2008). Cyber safety is about keeping safe online. The potential risks that young people face online include being bullied, stalked, harassed and exposed to identity fraud and inappropriate 
or damaging material such as illegal content, spam and computer viruses. The studies above have indicated that text messaging, emailing and chatroom postings are the most common means of cyberbullying. The frequencies of these practices could only increase with mobile technologies that are convenient to use. Unlike physical bullying where the perpetrator is known, the cyber perpetrator could be difficult to identify. Hence inculcating privacy and cybersafety literacies as well as online etiquette in individuals is imperative for successful and safe participation in online communities.

While the virtual world provides young people with opportunities to try out new ideas and take on different personas, an mLearningliterate individual would be aware that there could be possible undesirable consequences for the actions that they take. (S)he should appreciate the fact that his/her online conversations, text or phone messages may well be recorded permanently and what (s)he may think is private is in fact public. The fostering of this type of awareness as well as teaching about the ethics and cultural issues associated with digitally-based environments should be a part of the mLearning literacy education of students (Berson \& Berson, 2003).

Hence an mLearning literate individual would develop appropriate attitudes in using mobile technologies for socialising and learning by:

- Observing 'netiquette' by applying the similar rules as in face-to-face communication such as respect and using appropriate abbreviated/SMS language to avoid misinterpretation and misunderstanding;

- Being aware that SMS language can impact formal language usage in classroom situations;

- Balancing the amount of time spent on social networking sites and the amount of text messages sent in managing costs, time to do other things and prevention of social networking addiction;

- Protecting the individual's safety and privacy by keeping personal information as private as possible and not disclosing any more personal information than is necessary;

- Interpreting SMS and social network messages in terms of the tone of the message (e.g. use of bold letters and symbols) and underlying meanings correctly;

- Recognising when(s)he is being threatened and know how to deal with it, for example whether to ignore, report or respond to the threat;

- Being ethically literate and exercise moral judgement in using online materials and participating in online activities.

\section{Critical Literacy}

As shown in Figure 3, central to the development of the three dimensions of mLearning literacy is critical literacy - the ability to analyse and critique the relationships between texts, power and social justice that involves challenging the values and beliefs that lie beneath the surface of texts. 'Texts' in this context includes images, spoken and written words, music, songs, novels, conversations, movies and other multimedia materials (Coffey, not dated). As the amount of digital information that is readily available to us in different formats via mobile devices increases, developing skills to critically analyse the multitude of 'texts' to make meaning from it is an important part of mLearning education. Freebody \& Luke (1990) developed a repertoire of capabilities in their four-part resource model for critical literacy, these being: code breaker (coding competence), meaning maker (semantic competence), text user (pragmatic competence) and text critic (critical competence). The kinds of questions to ask for each component of the model have also been identified (see Luke, 2000).

Critical literacy is not limited to critiquing online content and opinions e.g. on contemporary issues like climate change, it also applies to social networking via the Internet or mobile network, where conversations and opinions are shaped by the worldviews of the people in the conversation and may be biased in their expres- 
sions. At the technical level, critical literacy has a role in understanding how each type of technology provides the capacity to shape the texts and the choices made by the creator in assembling the digital material to represent his/her thinking.

As an example of mLearning literacy in practice, students using iPads could be asked to peer review an assignment set by the teacher using the annotation features available on the Good Reader application (see Figure 4). At the technical level, the student will need to know how to use the various features - when to tap, double tap, hold, draw bubbles, highlight, strike text, use sticky note etc. At the cognitive level, the student would need to be able to analyse the text critically and select the most appropriate feature(s) to annotate and provide feedback, e.g. for short comments, (s)he could highlight and then write freeform with the finger a 1-2 word comment (such as 'good', 'well argued') or for longer comments, to use the sticky note and type in the comments. At the sociol-emotional level, the student will need to be sensitive in their choice of words for the comments as well as the annotation styles (e.g. using bold or capital letters) in order to convey the message in a constructive manner.

\section{IMPLICATIONS OF MLEARNING LITERACY FOR EDUCATORS}

Educators embracing programs that make use of mobile devices for learning need to ensure that students' mLearning literacy is adequately developed in order to achieve better learning outcomes. In particular, the technical and functional dimensions of mLearning literacy need attention as studies have shown that one of the barriers to using mobile devices for learning for both staff and students is the lack of awareness of the functionalities of the mobile device being used and the limited knowledge of the academic applications of the mobile devices (Belanger, 2007; Goodchild \& Chenery-Morris, 2011; Stiler, 2007).

By being skilled technically with working with the features of the mobile device in use,

Figure 4. iPad screen shots of Good Reader annotation capabilities. Source from http://itunes. apple.com/au/app/goodreader-for-ipad/id363448914? $m t=8$
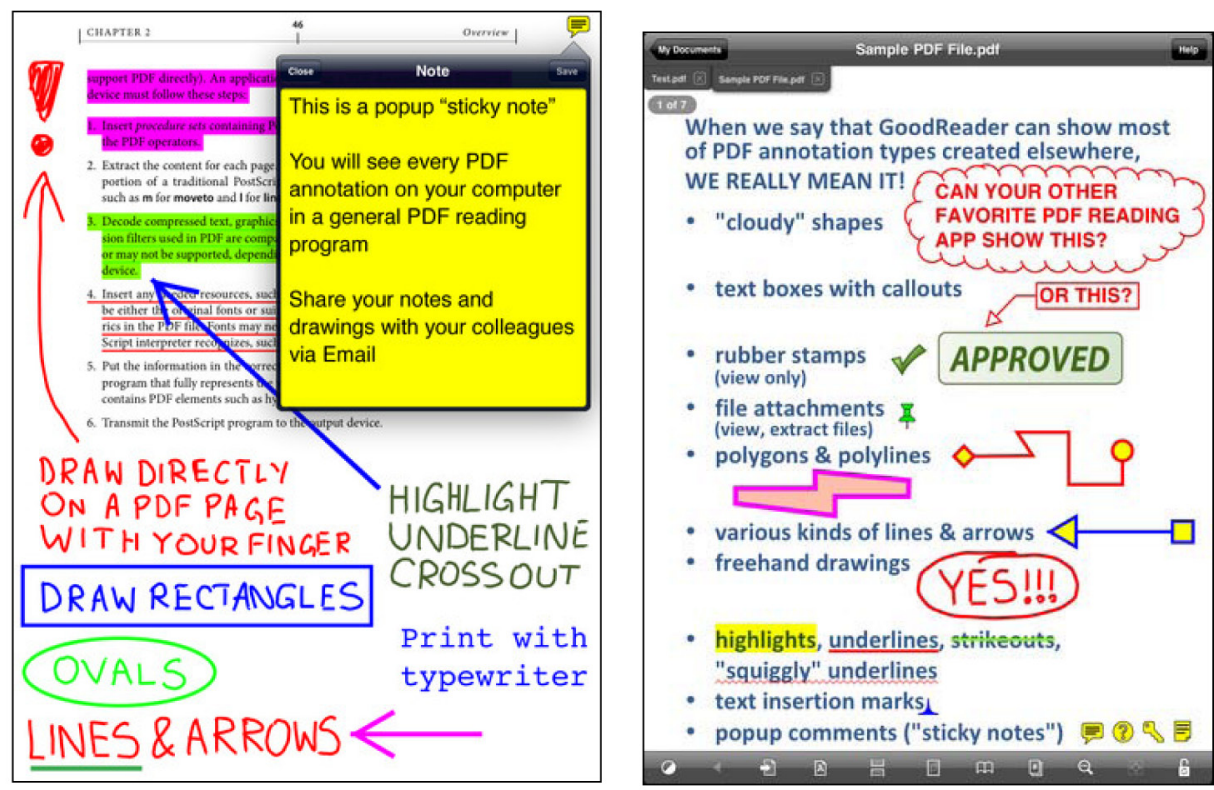

Copyright (C) 2013, IGI Global. Copying or distributing in print or electronic forms without written permission of IGI Global is prohibited. 
the student does not have to be distracted by the technology, would be able to work intuitively with the technology and would be able to focus the working memory on learning the material and undertaking the task at hand. In other words, it reduces the cognitive load imposed on the brain during the learning. Apart from the technical skills, well developed cognitive and social-emotional skills for mLearning will prepare students to access and use information with their mobile devices intelligently, ethically and safely. This is important as with the increased personal ownership and the ease in portability of mobile devices, it means that the frequency of accessing Internet sites increases during informal learning times.

There is a role for teachers to foster the development of mLearning literacy in all students, irrespective of whether there is a mobile learning program in the school. With the vast majority of school aged students owning mobile phones and other mobile devices, there is much more informal learning and socialization happening. Hence it would be an advantage to provide students with opportunities to develop mLearning literacy, particularly associated with the use of mobile phones. There are two reasons for schools not adopting mobile phones for learning (i) mobile phones are banned from classrooms due to their perceived disruptive nature and (ii) in a crowded curriculum, there is little space to integrate any more teaching or curriculum material. While it is not necessary (although still a good idea) to embrace mobile phones, especially smartphones, in the mainstream curriculum, devoting some time (1-2 weeks) for intensive exploration and learning about mobile phones would help students develop mLearning literacy. One example would be after the end-of-the-year schools' exams where time is often devoted to extra-curricular activities. It would be an appropriate time to open up nonbanned mobile phone (or other mobile devices that students have e.g. iPods, tablets) usage. The learning will be dedicated to the sharing of mobile phone uses and experiences, exploring the different features of different phones and their usage through undertaking small set tasks, critiquing text messages and discussing safety and etiquette issues associated with mobile phone usage.

Another implication of mLearning literacy is that teachers need to be similarly literate if they are to be involved in mLearning programs. This means developing adequate technical skills with and knowledge of the mobile device(s) used in the classroom. Good technical skills and knowledge of the affordances and constraints of the mobile device(s) in use will enable the teacher to design pedagogically sound uses of the mobile device. Research has shown that one of the main barriers of effective and sustainable integration of technology in schools is a lack of technical skills and knowledge in teachers (Hew \& Brush, 2007; Mishra \& Koehler, 2006; Ng \& Gunstone, 2003; Tebbutt, 2000). In order to be technically mLearning-literate, teachers must be provided with professional development and time to practise and familiarise themselves with the technology. Similar to students' learning, when teachers are technically skilled and familiar with the pedagogical potential of the mobile device, they can focus on the pedagogy and teaching of the concepts that the students need to learn. They do not have to split their attention and pause to trouble shoot due to unfamiliarity with the technical features.

In schools where there is formal learning that uses mobile devices as the support tool, the teacher needs to structure a series of small but explicit exercises that draw on the different affordances of the mobile device and its applications to build up the students' understanding of how the device could be used for learning. For example, in using spreadsheets (Numbers in iPads, Mobile Excel in PDA, Excel in Documents To Go app for Android tablets), exercises that are designed to take them through data entry, using the 'sum', 'average' and other functions, writing formulae and charting different graphs for different purposes will provide them with the opportunity to learn about the software before applying it to problem solving tasks. The exercises will also allow them to understand 
the constraints in using mobile-based spreadsheets in comparison to desktop/laptop-based spreadsheets.

\section{CONCLUSION}

The mLearning literacy framework described in this paper is made up of the three dimensions of technical, cognitive and social-emotional and considers both competencies and affective attributes. The framework demonstrates that mLearning literacy is a credible concept which differs quite significantly from conventional digital literacy. Currently, the uptake of formal mobile learning in educational institutions is still small and reports on mLearning are often accounts of funded initiatives or specific projects for specific domain knowledge acquisition. Hence, while it is easier to argue for a place to assess students' general digital literacy, it is more difficult to argue for the formal assessment of mLearning literacy. But as mobile technologies continue to evolve to become more advanced in functionalities and processing power, and as ownership of mobile devices increases, learning with the devices will become more significant. Hence, there is a role for educators to foster the development of mLearning literacy in their students. With the technological evolution of mobile devices not appearing to slow down, it could be argued that the one sustaining aspect of using mobile devices for both learning and personal growth is mLearning literacy. Proficiency in mLearning literacy would prepare the individuals to adapt to new mobile technologies easily and empower them to use them effectively and sensibly for learning and everyday activities. Hence it is one of the life skills-based literacy that educational institutions, particularly schools (where the ownership of mobile phones begin) should pay attention to and embrace as part of the curriculum.

\section{REFERENCES}

Alani, N. S. (2009). Mobile literacy: An integral research approach-using respect \& instinct to reach the heart of mobile design issues. Retrieved December 6, 2011, from http://adaptivepath.com/ideas/ mobile-literacy-an-integral-research-approachusing-respect-instinct-to-rea

Atherton, J. S. (2011) Learning and teaching; Conversational learning theory; Pask and laurillard. Retrieved August 6, 2012, from http://www. learningandteaching.info/learning/pask.htm

BBC. (2008). Mobile internet usage on the rise. Retrieved March 8, 2011, from http://news.bbc. co.uk/2/hi/technology/7748372.stm

Beetham, H., McGill, L., \& Littlejohn, A. (2009). Thriving in the $21^{\text {st }}$ century: Learning literacies for a digital age (LLiDA). JISC final report. Retrieved July 20, 2012 from http://www.jisc.ac.uk/media/ documents/projects/llidareportjune2009.pdf

Belanger, Y. (2007). The iPod revolution: Coming to a classroom near you. In Proceedings of the 2007 Organisational Systems Research Association Conference. Retrieved March 18, 2011 from http://www. osra.org/2007/papers/brookshire.pdf

Berson, I. R., \& Berson, M. J. (2003). Digital literacy for effective citizenship. Social Education, 67(3), 164-167.

Boitshwarelo, B. (2010). Proposing an integrated research framework for connectivism: Utilising theoretical synergies. International Review of Research in Open and Distance Learning, 12(3), 161-178.

Brown, J. S., Collins, A., \& Duguid, P. (1989). Situated cognition and the culture of learning. Educational Researcher, 18(1), 32-42.

Bruner, J. (1986). Actual minds, possible worlds. Cambridge, MA: Harvard University Press.

Chen, H.-R., \& Huang, H.-L. (2010). User acceptance of mobile knowledge management learning system: Design and analysis. Journal of Educational Technology \& Society, 13(3), 70-77.

Chen, Y. S., Kao, T. C., Sheu, J. P., \& Chiang, C. Y. (2002). A mobile scaffolding-aid based birdwatching learning system. In U. Hoppe, M. Milrad \& Kinshuk(Eds), Proceedings of IEEE International Workshop on Wireless and Mobile Technologies in Education (WMTE'02)(pp. 15-22). New York, NY: IEEE Computer Society Press. 
Cheung, W. S., \& Hew, K. F. (2009). A review of research methodologies used in studies on mobile handheld devices in K-12 and higher education settings. Australasian Journal of Educational Technology, 25(2), 153-183.

Chu, H.-C., Hwang, G.-J., \& Tsai, C.-C. (2010). A knowledge engineering approach to developing mindtools for context-aware ubiquitous learning. Computers \& Education, 54(1), 289-297. doi:10.1016/j.compedu.2009.08.023.

Clough, G., Jones, A. C., McAndrew, P., \& Scanlon, E. (2008). Informal learning with PDAs and smartphones. Journal of Computer Assisted Learning, 24(5), 359-371. doi:10.1111/j.13652729.2007.00268.x.

Cochrane, T., \& Bateman, R. (2010). Smartphones give you wings: Pedagogical affordances of mobile Web 2.0. Australasian Journal of Educational Technology, 26(1), 1-14.

Coffey, H. (not dated). Critical literacy. Retrieved May 12, 2011, from http://www.learnnc.org/lp/ pages $/ 4437$ ?style $=$ print

Conroy, S. (2007). Labor's plan for cyber-safety (fact sheet). Retrieved May 12, 2011, from http:// machinegunkeyboard.com/ausnetcensorship/labors_plan_for_cyber_safety.pdf

Dale, C., \& Pymm, J. M. (2009). Podagogy: The iPod as a learning technology. Active Learning in Higher Education, 10(1), 84-96. doi:10.1177/1469787408100197.

Dyson, L. E., Litchfield, A., Lawrence, E., Raban, R., \& Leijdekkers, P. (2009). Advancing the m-learning research agenda for active, experiential learning: Four case studies. Australasian Journal of Educational Technology, 25(2), 250-267.

El-Bishouty, M., Ogata, H., \& Yano, Y. (2011). Visualizing knowledge awareness support in ubiquitous learning. In W. $\mathrm{Ng}$ (Ed.), Mobile technologies and handheld devices for ubiquitous learning: Research and pedagogy (pp. 15-29). Hershey, PA: IGI Global Publishing.

Eshet-Alkalai, Y. (2004). Digital literacy: A conceptual framework for survival skills in the digital era. Journal of Educational Multimedia and Hypermedia, 13(1), 93-106.

ETS (Educational Testing Services). (2007). Digital transformation: A framework for ICT literacy. Princeton, NJ: ETS.
Evans, C. (2008). The effectiveness of m-learning in the form of podcast revision lectures in higher education. Computers \& Education, 50(2), 491-498. doi:10.1016/j.compedu.2007.09.016.

Franklin, T., Sexton, C., Lu, Y., \& Ma, H. (2007). PDAs in teacher education: A case study examining mobile technology integration. Journal of Technology and Teacher Education, 15(1), 39-57.

Freebody, P., \& Luke,A. (1990). Literacies programs: Debates and demands in cultural context. Prospect: Australian Journal of TESOL, 5(7), 7-16.

Gawelek, M. A., Spataro, M., \& Komarny, P. (2011). Mobile perspectives: On iPads-why mobile? EDUCAUSE Review, 46(2). Retrieved December 7, 2011 from http://www.educause.edu/ EDUCAUSE+Review/EDUCAUSEReviewMagazineVolume46/iMobilePerspectivesOniPadsibrW/226163

Geogiev, T., Georgieva, E., \& Smrikorov, A. (2004). M-learning: A new stage of e-learning. In Proceedings of International Conference on Computer Systems and Technologie, Rousse, Bulgaria. Retrieved December, 8 2011, from http://ecet.ecs.ru.acad.bg/ cst04/Docs/sIV/428.pdf

Gkatzidou, S., \& Pearson, E. (2009). The potential for adaptable accessible learning objects: A case study in accessible vodcasting. Australasian Journal of Educational Technology, 25(2), 292-307.

Goodchild, T., \& Chenery-Morris, S. (2011). Educational podcasts at university campus. In W. $\mathrm{Ng}$ (Ed.), Mobile technologies and handheld devices for ubiquitous learning: Research and pedagogy (pp. 187-208). Hershey, PA: IGI Global Publishing.

Hague, C., \& Payton, S. (2010). Digital literacy across the curriculum. UK. Berkshire: Futurelab.

Hanewald, R. (2008). Confronting the pedagogical challenge of cyber safety. Australian Journal of Teacher Education, 33(3), 1-16.

Hedin, B., \& Norén, J. (2009, February 26-28). Location-based m-learning reminders. In I. A. Sánchez \& P. Isaías (Eds.), Proceedings of the IADIS International Conference Mobile Learning 2009, Barcelona, Spain (pp. 3-10).

Herrington, J., Herrington, A., Mantei, J., Olney, I., \& Ferry, B. (2009). Using mobile technologies to develop new ways of teaching and learning. In J. Herrington, J. Mantei, I. Olney, B. Ferry, \& A. Herrington (Eds.), New technologies, new pedagogies: Mobile learning in higher education (pp. 1-14). Wollongong, NSW: University of Wollongong. 
Hew, K.F., \& Brush, T.(2007). Integrating technology into K-12 teaching and learning: Current knowledge gaps and recommendations for future research. $E d u$ cational Technology Research and Development, 55, 223-252. doi:10.1007/s11423-006-9022-5.

Huang, J. J. S., Yang, S. J. H., Huang, Y. M., \& Hsiao, I. Y. T. (2010). Social learning networks: Build mobile learning networks based on collaborative services. Journal of Educational Technology \& Society, 13(3), 78-92.

Hung, P. H., Lin, Y. F., \& Hwang, G. J. (2010). Formative assessment design for PDA integrated ecology observation. Journal of Educational Technology \& Society, 13(3), 33-42.

John-Steiner, V., \& Mahn, H. (1996). Sociocultural approaches to learning and development: A Vygotskian framework. Educational Psychology, 31, 191-206

Keegan, D. (2005), The incorporation of mobile learning into mainstream education and training. In Proceedings of the 4th World Conference on MLearning, Cape Town South Africa (pp. 1-17).

Lankshear, C., \& Knobel, M. (2003). New literacies: Changing knowledge and classroom learning. Buckingham, UK: Open University Press.

Lankshear, C., \& Knobel, M. (2007). Sampling "the new" in new literacies. In M. Knobel, \& C. Lankshear (Eds.), A new literacies sampler (pp. 1-24). New York, NY: Peter Lang.

Laurillard, D. (2002). Rethinking university teaching: A conversational framework for the effective use of learning technologies. London, UK: Routledge. doi:10.4324/9780203304846.

Laurillard, D. (2007). Pedagogical forms for mobile learning. In N. Pachler (Ed.), Mobile learning: towards a research agenda (pp. 153-175). London, UK: WLE Centre, IoE.

Lave, J., \& Wenger, E. (1990). Situated learning. Legitimate periperal participation. Cambridge, UK: Cambridge University Press.

Leu, D. J. Jr, Kinzer, C. K., Coiro, J., \& Cammack, D. W. (2004). Toward a theory of new literacies emerging from the internet and other information and communication technologies. In R. B. Ruddell, \& N. J. Unrau (Eds.), Theoretical models and processes of reading (pp. 1570-1613). Newark, DE: International Reading Association.
Liaw, S. S., Hatala, M., \& Huang, H. M. (2010). Investigating acceptance toward mobile learning to assist individual knowledge management: Based on activity theory approach. Computers \& Education, 54(2), 446-454. doi:10.1016/j.compedu.2009.08.029.

Littlejohn, A., Beetham, H., \& McGill, L. (2012). Learning at the digital frontier: A review of digital literacies in theory and practice. Journal of Computer Assisted Learning [Online]. Retrieved July 20, 2012, from http://dx.doi.org/10.1111/j.13652729.2011.00474.x

Looi, C. K., Seow, P., Zhang, B., So, H. J., Chen, W., \&Wong, L.H. (2010). Leveraging mobile technology for sustainable seamless learning: A research agenda. British Journal of Educational Technology, 41(2), 154-169. doi:10.1111/j.1467-8535.2008.00912.x.

Luke, A. (2000). Critical literacy in Australia: Amatter of context and standpoint. Journal of Adolescent \& Adult Literacy, 43(5), 448-461.

Martin, A. (2005). DigEuLit - A European framework for digital literacy: A progress report. Journal of eLiteracy, 2, 130-136.

Mishra, P., \& Koehler, M. J. (2006). Technological pedagogical content knowledge: A new framework for teacher knowledge. Teachers College Record, 108(6), 1017-1054. doi:10.1111/j.14679620.2006.00684.x.

Motiwalla, L. F. (2007). Mobile learning: A framework and evaluation. Computers \& Education, 49(3), 581-596. doi:10.1016/j.compedu.2005.10.011.

Murphy, J.(2010). Mobile literacy: Competencies for mobile tech. Retrieved December 7, 2011, from http:// prezi.com/u9urpn3pw9xo/cil2010-mobile-literacy/

W. Ng (Ed.). (2011a). Mobile technologies and handheld devices for ubiquitous learning: Research and pedagogy. Hershey, PA: IGI Global Publishing.

Ng, W. (2011b). mLearning literacy. In Proceedings of the $10^{\text {th }}$ International Conference on Mobile Learning, Beijing, China, p. 162-171.

$\mathrm{Ng}$, W. (2012). Empowering scientific literacy through digital literacy and multiliteracies. New York, NY: Nova Science Publisher.

Ng, W., \& Gunstone, R. (2003). Science and computer-based technologies in Victorian government schools: Attitudes of secondary science teachers. Journal of Research in Science and Technology Education, 21(2), 243-264. doi:10.1080/0263514 032000127266. 
$\mathrm{Ng}, \mathrm{W} .$, \& Nicholas, H. (in press). A framework for sustainable mobile learning in schools. British Journal of Educational Technology. Retrieved from http://onlinelibrary.wiley.com/doi/10.1111/j.14678535.2012.01359.x/full\#sf

Nicholas, H., \& Ng, W. (2009). Ubiquitous learning and handhelds: An overview of theory and pedagogy. In P. Rogers, G. Berg, J. Boettcher, C. Howard, L. Justice, \& K. Schenk (Eds.), Encyclopedia for online and distance learning (Vol.IV, pp.2171-2176). Hershey, PA: IGI Global Publishers. doi:10.4018/9781-60566-198-8.ch321.

Nixon, H., Atkinson, S., \& Beavis, C. (2006). New media pathways: Navigating the links between home, school and the workplace. In L. W. H. Tan, \& R. Subramaniam (Eds.), Handbook of research on literacy in technology at the K1-2 level (pp. 118-136). Hershey, PA: Idea Group Publishing. doi:10.4018/978-1-59140-494-1.ch007.

Ogata, H., \& Yano, Y. (2004). Context-aware support for computer supported ubiquitous learning. In J. Roschelle, T. W. Chan, Kinshuk, S. Yang (Eds.), Proceedings of the 2nd IEEE (WMTE2004) (pp. 27-34). New York, NY: IEEE Press.

Orr, G. (2010). A review of literature in mobile learning: Affordances and constraints. In Proceedings of the $6^{\text {th }}$ IEEE International Conference on Wireless, Mobile and Ubiquitous Technologies in Education (pp. 107 -111). New York, NY: IEEE Press.

Pachler, N. (2009). Research methods in mobile and informal learning: Some issues. In G. Vavoula, N. Pachler, \& A. Kukulska-Hulme (Eds.), Researching mobile learning: Frameworks, tools and research designs (pp. 1-15). Oxford, UK: Peter Lang Publishing.

Parry, D. (2011). Mobile perspectives: On teaching mobile literacy. EDUCAUSE Review, 46(2). Retrieved December 7, 2011, from http://www.educause.edu/EDUCAUSE+Review/EDUCAUSEReviewMagazineVolume46/iMobilePerspectivesOnteachingi/226160

Parsons, D. (2007). Mobile learning. In D. Taniar (Ed.), Encyclopedia of mobile computing and commerce (pp. 525-527). Hershey, PA: IGI Global Publishing. doi:10.4018/978-1-59904-002-8.ch087.

Pask, G. (1976). Conversation theory: Applications in education and epistemology. Amsterdam, Netherlands: Elsevier.
Semali, L. (2001, November). Defining new literacies in curricular practice. Reading Online, 5(4). Retrieved July 10, 2012, form http://www.readingonline.org/ newliteracies/lit_index.asp?HREF=semali1/index. html

Sharples, M., Taylor, J., \& Vavoula, G. N. (2007). A theory of learning for the mobile age. In R. Andrews, \& C. Haythornthwaite (Eds.), The SAGE handbook of e-learning research (pp. 221-247). London, UK: Sage. doi:10.4135/9781848607859.n10.

Shih, J. L., Chuang, C. W., \& Hwang, G. J. (2011). Historic monument education: The impact of a collaborative inquiry-based mobile learning strategy on social relationship development. In W. $\mathrm{Ng}$ (Ed.), Mobile technologies and handheld devices for ubiquitous learning: Research and pedagogy (pp. 138-169). Hershey, PA: IGI Global Publishing.

Shim, J. P., Shropshire, J., Park, S., Harris, H., \& Campbell, N. (2007). Podcasting for e-learning, communication, and delivery. Industrial Management \& Data Systems, 107(4), 587-600. doi:10.1108/02635570710740715.

Siemens, G. (2005). Connectivism: A learning theory for the digital age. International Journal of Instructional Technology \& Distance Learning, 2(1), 3-9.

Sitthiworachart, J. (2007). Interactive mobile learning: Using PDAs for higher education in humancomputer interaction study. In R. Carlsen et al. (Eds.), Proceedings of Society for Information Technology \& Teacher Education International Conference 2007(pp. 2105-2110). Chesapeake, VA: AACE.

Stiler, G. M. (2007). MP3 players: Application and implications for the use of popular technology in secondary schools. Education, 128(1), 20-33.

Street, B. V. (1995). Social literacies: Critical approaches to literacy development, ethnography and education. London, UK: Longman.

Tebbutt, M. (2000). ICT in science: problems, possibilities... and principles? The School Science Review, 81(297), 57-64.

The New London Group. (1996). A pedagogy of multiliteracies: Designing social futures. Harvard Educational Review, 66(1), 60-92.

Tsai, P.-S., Tsai, C.-C., \& Hwang, G.-H. (2010). Elementary school students' attitudes and self-efficacy of using PDAs in a ubiquitous learning context. Australasian Journal of Educational Technology, 26, 297-308. 
UNESCO. (2004). The plurality of literacy and its implications for policies and programmes. Paris, France: UNESCO.

Vygotsky, L. S. (1978). Mind in society: The development of higher psychological processes. Cambridge, UK: Harvard University Press.

Whitney, L. (2009). AdMob: iPhones, Android phones on the rise. Retrieved December 7, 2011, from http://news.cnet.com/8301-1035_3-1036619394.htm

\section{ENDNOTES}

1 http://cnettv.cnet.com/tablet-war-heatsup/9742-1_53-50096867.html (accessed 4 January 2012)

iPad 2 with added functions e.g. dual cameras, was released on 25 March 2011 http:/www.rapidsms.org/case-studies/ senegal-the-jokko-initiative/ https://edutechdebate.org/meducation-initiatives/sms4learning-supporting-healthcareproviders-through-frontlinesmslearn/ http://www.cam.ac.uk/research/news/mobilecommunications-for-medicine/

Wan Ng (PhD) is Associate Professor in Technology-Enabled Learning and Teaching and Science Education at the University of New South Wales, Australia. Her research interests are located within science education, gifted education and teachers'work. Underpinning the research in these areas are studies of effective ICT-embedded pedagogy that include the use of online and mobile technologies in learning and teaching. Wan has written widely for an international audience, her most recent publications are an edited book titled Mobile Technologies and Handheld Devices for Ubiquitous Learning: Research and Pedagogy and an authored book titled Empowering Scientific Literacy through Digital Literacy and Multiliteracies. 